\title{
Type V Collagen Distribution in Liver Is Reconstructed in Coculture System of Hepatocytes and Stellate Cells; The Possible Functions of Type V Collagen in Liver under Normal and Pathological Conditions
}

\author{
Kaori Kajihara Takai, Shunji Hattori*, and Shinkichi Irie \\ Nippi Research Institute of Biomatrix, Adachi-ku, Tokyo, 120-8601, Japan
}

\begin{abstract}
The contents of type I, type III and type V collagen and the collagen type specific distributions in liver under normal and cirrhotic conditions were examined. In $\mathrm{CCl}_{4}$ injected rat, the increasing amount of type $\mathrm{V}$ collagen was a specific event during the progression of cirrhosis. In normal liver, immunohistochemical observation showed that type $V$ collagen was localized on the fine fibrils, while type I was localized on the thick fibril. Type V collagen was partially colocalized with type IV collagen. In the cirrhotic liver, type V collagen was localized on the margin of the thick fibrous septa along with type IV collagen. Type I collagen existed in the core region of fibrous septa where the stellate cells were prominent. To elucidate the mechanism of the type specific deposition of collagen in the liver, we constructed a coculture system using both stellate cells and hepatocytes. In this system, type $V$ collagen was mainly deposited on hepatocyte colonies not on stellate cells, while type I collagen fibrils were localized on stellate cells. The spatial positioning of type $I$ and type $V$ collagens in vitro was similar to that in the liver. In the cell adhesion assay, the adhesion of stellate cells to type $V$ collagen was poorer than that of the hepatocytes. The collagen type-specific affinity of the stellate cells and hepatocytes may explain the specific localization of type $\mathrm{V}$ collagen in the liver and coculture system. These results suggested that the functions of type $\mathrm{V}$ collagen are not only to connect type IV collagen with type I collagen fibril, but also to protect the parenchyma from excess type I collagen deposition produced by stellate cells under pathological conditions.
\end{abstract}

Key words: type V collagen/cirrhosis/coculture/hepatocyte/stellate cell

Collagens form the main framework of connective tissue in various organs including liver. There are two types of collagen fibril in liver reported, one is a fine reticular fiber which are composed of type III and type V collagen, and other is the coarse reticular fiber which is mainly composed of type I collagen (Adachi et al., 1991). In cirrhosis, abundant deposition of collagen was observed at the fibrous septa by immunohistochemical method. Under pathological conditions, stellate cells change their shape to

\footnotetext{
*To whom correspondence should be addressed: Shunji Hattori PhD. Nippi Research Institute of Biomatrix, 1-1 Senjumidori-cho, Adachi-ku, Tokyo, 120-8601, Japan.

Tel: +81-3-3888-5111, Fax: +81-3-3870-9631

E-mail: shunhatt@bekkoame.ne.jp

Abbreviations: DAPI, 4', 6-diamino-2-phenylindole; DMEM, Dulbecco's modified Eagle's medium; EDTA, ethylenediamine tetraacetic acid; FBS, fetal bovine serum; G3PDH, glyceraldehyde-3-phosphate dehydrogenase; HCGM, hepatocyte growth medium; HEPES, N-2 hydroxyethylpiperazine-N'-2-ethane sulfuric acid; NEM, $N$-ethylmaleimide; PBS, phosphate buffered saline; PI, propidium iodide; PMSF, phenylmethylsulfonyl fluoride; SMA, smooth muscle actin
}

myofibroblastic ones, and then proliferate, expressing $\alpha$ smooth muscle actin ( $\alpha$ SMA), to synthesize a large amount of type I and type III collagen. (Ogawa et al., 1986; Geerts et al., 1991; Friedman, 1993; Gressner, 1996). Various serum markers that can be used to evaluate the progression of hepatic fibrosis have also been reported (Tanikawa, 1994; Tsutsumi et al., 1996). Pro-type III collagen and the triplehelical domain and 7S domain of type IV collagen are used as the serum markers for cirrhosis (Obata et al., 1989; Misaki et al., 1990; Murawaki et al., 1996). In cirrhosis, several types of collagen increase at various ratios (Rojkind and Ponce-Noyola, 1982; Murata et al., 1984).

In this report, we show that type $\mathrm{V}$ collagen increases with the progression of fibrosis, and we propose that type $\mathrm{V}$ collagen could be used as an index of cirrhosis. Type V collagen is widely distributed in many tissues such as the skin, placenta and cornea, and is one of the fibrillar collagens that has the potential to form fibrils (Adachi and Hayashi, 1986). First, type V collagen has been identified as one of the components of the lamina densa together with type IV collagen 
(Roll et al., 1980). Type V collagen is located in the lamina fibroreticularis and anchors its basement membrane on the stroma. It has also been postulated that type V and type XI collagen influence the growth of type I and type II collagen fibrils, respectively (Adachi and Hayashi, 1986; Mendler et al., 1989; Birk et al., 1990). Using a self-assembly system, it has been demonstrated that the diameter of heterotypic type I / V collagen fibrils becomes thinner as the ratio of type $\mathrm{V}$ collagen to type I collagen increases (Adachi and Hayashi, 1986; Marchant et al., 1996). Under woundhealing circumstances, a change in the fibril diameter was observed, and a decrease in collagen fibril thickness in cirrhosis has also been reported (Scott et al., 1994). These observations imply that type $\mathrm{V}$ collagen plays a role in such inflammatory reactions.

The extracellular matrix (ECM), including collagen, plays an important role in the major programs of the cell functions including growth, differentiation and apoptosis. The ECM controls the expression of tissue-specific genes (Caron, 1990; Mooney et al., 1992). These cell functions are regulated through cell surface receptors such as integrins (Hynes, 1992; Yamada, 1997). Thus, it is expected that the increase in type $\mathrm{V}$ collagen that occurs in cirrhosis would influence cell functions. To investigate the effect of type V collagen on liver-derived cells, an in vitro assay system was developed. In this study, we propose just such a useful culture system, namely, a coculture of parenchymal hepatocytes and activated stellate cells. Cocultures of parenchymal cells with nonparenchymal cells have been proposed by several investigators (Rojkind et al., 1995; Bader et al., 1996; Tateno et al., 2000). These studies have been primarily concerned with the maintenance of the differentiated functions of hepatocytes and have shown that the presence of nonparenchymal cells is essential for such maintenance to succeed.

In the present study, we examined the changes of type I, IV and V collagen distributions in the liver under normal and pathological conditions. Further, we investigated the role of type $\mathrm{V}$ collagen in a coculture system using primary parenchymal hepatocytes and activated stellate cells, a system that reproduces some aspects of the collagen type specific localization observed in vivo.

\section{Materials and methods}

\section{Induction of cirrhosis}

Male Fischer-344 rats (10 weeks old) were obtained from Charles River Breeding Laboratories, Inc., Detroit, Michigan. These rats were maintained at a controlled temperature $\left(23^{\circ} \mathrm{C}\right)$ under daily cycles of alternating 12-hour periods of light and darkness. Fibrosis and cirrhosis were induced in rats by subcutaneous injection of $\mathrm{CCl}_{4}(0.2 \mathrm{ml} / 100 \mathrm{~g}$ body weight in $50 \%$ olive oil; Wako Pure Chemical Co., Japan), twice a week for either 7 weeks or 10 weeks (Unakar, 1966; Wu and Norton, 1996). As the controls of fibrosis and cirrhosis, two groups of non-injected rats were maintained under the same conditions for either 7 weeks or 10 weeks. In each group, 3 rats were used and we conducted the same experiment twice independently. All experiments were carried out according to the guidelines of our institutional animal committee. The livers were perfused with phosphate buffer when the rats were sacrificed under anesthesia. The tissue was frozen immediately in liquid nitrogen and was stored at $-80^{\circ} \mathrm{C}$ until use.

\section{Preparation of type I and type $V$ collagens}

Type I and type V collagen were extracted from fetal bovine skin for the cell adhesion assay. Type I collagen was extracted with 50 $\mathrm{mM}$ acetic acid at $4{ }^{\circ} \mathrm{C}$ and treated with pepsin $(1 \mathrm{mg} / \mathrm{ml})$. Type $\mathrm{V}$ collagen was extracted using pepsin $(1 \mathrm{mg} / \mathrm{ml}$ in $0.5 \mathrm{M}$ acetic acid at $4{ }^{\circ} \mathrm{C}$ ) and purified by differential salt precipitation at $0.7 \mathrm{M}$ and $1.2 \mathrm{M} \mathrm{NaCl}$ in $0.5 \mathrm{M}$ acetic acid (Yamagata et al., 1982).

Rat skin type I, type III and type V collagen were extracted with pepsin treatment $\left(1 \mathrm{mg} / \mathrm{ml}\right.$ in $0.5 \mathrm{M}$ acetic acid at $\left.4^{\circ} \mathrm{C}\right)$ and purified by salt precipitation. The concentration of purified collagen was measured by the Buret method.

\section{Analysis of collagens from the liver}

Livers from normal and $\mathrm{CCl}_{4}$ treated rats were washed with a phosphate buffer that contained ethylenediamine tetraacetic acid (EDTA), $N$-ethylmaleimide (NEM) and phenylmethylsulfonyl fluoride (PMSF). Liver tissue was then homogenized and defatted with ethanol at $4^{\circ} \mathrm{C}$. Collagen was extracted with pepsin treatment $\left(1 \mathrm{mg} / \mathrm{ml}\right.$ in $0.5 \mathrm{M}$ acetic acid) for 24 hours at $4^{\circ} \mathrm{C}$. The extract was subjected to $5 \%$ sodium dodecyl sulfate (SDS)-polyacrylamide gel electrophoresis (PAGE) in the presence of 3.6 M urea (Hayashi and Nagai, 1980) for separating alpha chains of type I and type III collagen, and transferred onto PVDF membranes. After being blocked with $1 \%$ bovine serum albumin (BSA), the membranes were reacted with rabbit anti-mouse type $\mathrm{V}$ collagen antibody (reacted with rat type V collagen) (LSL Co., Japan). The bound antibody was detected by ECL reagent (Amersham Pharmacia Biotech, Buckinghamshire, UK). Both collagens from liver and skin were subjected to 5\% SDS-PAGE and visualized by Coomassie Blue staining. The amount of type $\mathrm{V}$ collagen was estimated by densitometric analysis of SDS-PAGE gel using "NIH image" software. To quantify the amount of each type of collagen, type I and type III and type V collagen extracted from rat skin were used for the standard, respectively. We undertook extractions and analyses of collagens independently using 3 each livers in normal, fibrotic and cirrhotic stage.

\section{Isolation and culture of hepatocytes and stellate cells}

Liver cells were prepared from 9- to 11-week-old male Fischer rats (190-232g) by two-step collagenase (Wako Pure Chemical Co. Oosaka, Japan) perfusion method (Seglen, 1976). Hepatocytes were obtained as precipitates by centrifugation at $50 \mathrm{G}$ for 1 minute (Tateno and Yoshizato, 1996). Purity of hepatocyte was more than $99 \%$ as judged by immunostaining with anti albumin 
antibody (Inter-cell Technologies, Inc., Hopewell, NJ). Viability was about $95 \%$ as determined by trypan blue exclusion test. Cells were cultured in a $5 \% \mathrm{CO}_{2}$ and $95 \%$ air atmosphere at $37^{\circ} \mathrm{C}$ in the hepatocyte growth medium [HCGM; Dulbecco's modified Eagle's medium (DMEM) supplemented with $10 \%$ fetal bovine serum (FBS), $20 \mathrm{mM} \mathrm{N}$-2-hydroxyethylpiperazine-N'-2-ethane sulfuric acid (HEPES), $30 \mu \mathrm{g} / \mathrm{ml} \mathrm{L-proline,} 0.5 \mu \mathrm{g} / \mathrm{ml}$ insulin, $10^{-7} \mathrm{M}$ dexamethasone, $44 \mathrm{mM} \mathrm{NaHCO} 3,10 \mathrm{mM}$ nicotinamide, $10 \mathrm{ng} / \mathrm{ml}$ epidermal growth factor, $0.2 \mathrm{mM} \mathrm{L}$-ascorbic acid 2-phosphate, and antibiotics including $100 \mathrm{IU} / \mathrm{ml}$ penicillin and $100 \mu \mathrm{g} / \mathrm{ml}$ streptomycin] (Tateno and Yoshizato, 1996). The medium was changed the next day and 4th day of culture. Dimethyl sulfoxide (DMSO) was added to the medium at a concentration of $1 \%$ after the 2nd medium change to reduce the growth of stellate cells (Tateno and Yoshizato, 1996).

Stellate cells were isolated from rat liver by percoll gradient centrifugation after collagenase perfusions as described (Senoo and Hata, 1993). Stellate cell fraction was concentrated as a layer in percoll gradient. Stellate cells were cultured in DMEM with $10 \%$ FBS in a $5 \% \mathrm{CO}_{2}$ and $95 \%$ air atmosphere at $37^{\circ} \mathrm{C}$. They were split every 3 or 4 days using $0.05 \%$ trypsin and $0.02 \%$ EDTA. During passaging of the cells, other types of contaminated cells disappeared. We used 25 to 29 passages of stellate cells which showed a constant growth and were not contaminated with other types of cells. Stellate cells were identified by desmin positive staining. The cells had a myofibroblastic shape, were in high proliferating-phase and expressed $\alpha$ SMA (Friedman, 1993). From these profiles, stellate cells were assumed to be in the activated phase.

Coculture of hepatocytes and stellate cells was performed as follows. Hepatocytes $\left(4 \times 10^{3}\right.$ cells $\left./ \mathrm{cm}^{2}\right)$ were plated on $13.5-\mathrm{mm}$ Sumilon Celldesks (Sumitomo Bakelite Co., Ltd., Japan). After 24 hours, the stellate cells $\left(1 \times 10^{3}\right.$ cells $\left./ \mathrm{cm}^{2}\right)$ were plated on the attached hepatocytes and were cultured for 6 more days. In the coculture system, the incubation period was indicated as the days of culture after the hepatocytes were plated. The terms "coculture", "stellate cell-culture" and "hepatocyte-culture" refer to a culture of stellate cells on hepatocytes, a culture of only stellate cells, and a culture only of hepatocytes, respectively.

\section{Immunofluorescence microscopy}

Cultured cells were washed with phosphate buffered saline (PBS) and were air-dried immediately. Cells were fixed in cold acetone for 5 minutes and washed with PBS including $0.1 \%$ Tween 20 . After blocking with $2 \%$ BSA in PBS, immunostaining was performed using rabbit anti-rat type I collagen antibody (LSL Co., Japan), rabbit anti-mouse type IV collagen antibody (LSL Co.) and rabbit anti-mouse type $\mathrm{V}$ collagen antibody (LSL Co.). After washing with the primary antibody, it was reacted with FITCconjugated anti-species specific anti-IgG antibody. Hepatocytes in the coculture were stained with Texas red conjugated rabbit antirat albumin antibody (Inter-cell Technologies, Inc., Hopewell, NJ). Desmin positive stellate cells were detected using rabbit antidesmin polyclonal antibody (Monosan, Uden, Holland). Nuclei were counterstained with 4', 6-diamino-2-phenylindole (DAPI) or propidium iodide (PI). Samples were observed under a fluorescence microscope (Axioskop, Carl Zeiss, Jena, Germany).

For the immunofluorescent staining, the frozen liver tissue was sliced into sections ( $8 \mu \mathrm{m}$ in thickness). The sections were fixed in cold acetone for 5 minutes. After blocking with 2\% BSA in PBS, immunostaining was performed using the anti collagen antibodies described above and rabbit anti-desmin antibody (Monosan, Uden, Holland). After washing with the primary antibody, it was reacted with FITC-conjugated anti-species specific anti-IgG antibody. Samples were observed under a confocal laser-scanning microscope (LSM410, Carl Zeiss, Jena Germany).

For the collagen double immunofluorescent staining, the liver sections and the cultured cells were fixed in cold acetone for 5 minutes. After being blocked with PBS containing BSA (2\%), the samples were sequentially stained with goat anti-collagen antibody and rabbit anti-collagen antibody. We used the following antibodies: goat anti-type I collagen antibody (Southern Biotechnology Associates, Inc., Birmingham, AL) and goat anti-type IV collagen antibody (Southern Biotech) as primary antibodies, and Cy3conjugated anti-goat IgG was used for detection of primary antibodies; rabbit anti-rat type I collagen antibody (LSL Co.), rabbit anti-mouse type IV collagen antibody (LSL Co.) and rabbit antimouse type V collagen antibody (LSL Co.) for the 2nd detection, and FITC- conjugated anti-rabbit IgG was used for detection. The sections were observed under confocal laser-scanning microscope. Stained cells were observed under fluorescence microscope after nuclei were counterstained with 4', 6-diamino-2-phenylindole (DAPI). After immunohistochemical observation, cells were fixed with $4 \%$ paraformaldehyde and stained with eosin. Hepatocytes were stained strongly with eosin.

\section{RT-PCR}

Total RNA was extracted from cultured cells using the QIAGEN RNeasy system (QIAGEN K.K. Tokyo, Japan) at 7 days. For RTPCR, firststrand cDNA was synthesized from each extracted RNA using the SuperScript preamplification system (Gibco BRL, Life Technologies, Inc., Rockville, MD). The 3' end sequence corresponding to the C-terminal pro-peptide and the non-coding region of pro- $\alpha 1(\mathrm{~V})$ collagen cDNA was amplified by PCR with the forward primer 5'-GGCTCCAACGATGAGGAAATG and the reverse primer 5'-AAAGTCGGTGAACATGATGTCC. The 3' end sequence corresponding to the $\mathrm{C}$-terminal pro-peptide and the noncoding region of pro- $\alpha 2(\mathrm{~V})$ collagen cDNA was amplified by PCR with the forward primer 5'-CCAGCAAATCCCCTGACAA and the reverse primer 5'-CATGAAACAAACTGGCCCAA. For the RT-PCR reaction with $\alpha$ smooth muscle actin ( $\alpha$ SMA) cDNA as the stellate cell specific marker, the forward primer 5'-TATCCGATAGAACACGGCATCA and the reverse primer 5-ATAGGCACGTTGTGAGTCACGC were designed (Knittel et al., 1996). To adjust the amount of template cDNA, a PCR reaction was performed with primers coding for the housekeeping gene, glyceraldehyde-3-phosphate dehydrogenase (G3PDH), forward 5'TCCACCACCCTGTTGCTGTA, and reverse 5-ACCACAGTC- 
CATGCCATCAC. Amplification products were subjected to electrophoresis with $1.5 \%$ agar gels and stained with ethidium bromide.

\section{Analyses of collagen from the cultured cells}

To analyze the collagen secreted into the cultured medium, the conditioned medium was treated with pepsin $(1 \mathrm{mg} / \mathrm{ml}$ in $0.5 \mathrm{M}$ acetic acid) at $4^{\circ} \mathrm{C}$. The conditioned medium was concentrated to 10-fold by centrifugation (1200 G, 10 minutes) with an ultrafree centrifugal filter device (Millipore Co., Bedford, MA). Condensed collagen fractions were analyzed by SDS-PAGE (5\%). Collagens were stained by Coomassie Brilliant Blue. Each collagen band was identified by western blotting using collagen-type specific antibodies (data not shown).

After being removed from the culture medium, cells were washed with a phosphate buffer containing EDTA, NEM and PMSF and scraped from the culture dishes. Cell fractions were treated with pepsin $\left(1 \mathrm{mg} / \mathrm{ml}\right.$ in $0.5 \mathrm{M}$ acetic acid at $\left.4^{\circ} \mathrm{C}\right)$ to extract the collagen fraction. Collagens which remained undigested were solubilized with a neutral buffer including SDS and $\beta$ mercaptoethanol at $60^{\circ} \mathrm{C}$ for 15 minutes. Samples were analyzed by SDS-PAGE (5\%).

\section{Exogenous addition of collagen to the cultured cells}

Type V collagen was extracted from rat skin and was purified by salt fractionation. Type $\mathrm{V}$ collagen in $5 \mathrm{mM}$ acetic acid was added to the hepatocyte-culture and the coculture (final concentration of $100 \mu \mathrm{g} / \mathrm{ml}$ ) on day 7. After 24 hours, exogenous type $\mathrm{V}$ collagen was detected by immunofluorescence microscopy using antimouse type V collagen antibody (LSL Co.).

FITC-labeled bovine type I collagen (Hattori et al., 1996) was added to the coculture at day 7 . After 24 hours, exogenous type I collagen was observed under a fluorescent microscope. FITC labeling had no effect on cell adhesion activity and fibril formation.

\section{Cell adhesion assay}

Using 96-well microwell plates (Nalge Nunc International, Rochester, NY) coated with type I collagen $(100 \mu \mathrm{g} / \mathrm{ml})$ or type V collagen $(100 \mu \mathrm{g} / \mathrm{ml})$ in DMEM at $37^{\circ} \mathrm{C}$ for 2 hours and blocked with $1 \%$ BSA for 1 hour, cells suspended in DMEM were plated onto the collagen-coated microwell plates (stellate cell, $2 \times 10^{4}$ cells/well; hepatocyte, $1 \times 10^{4}$ cells/well). After 30 minutes (stellate cells) or 40 minutes (hepatocytes), plates were shaken at $600 \mathrm{rpm}$ for 10 seconds by a microplate mixer, and unadherent cells were discarded. The adhered cells were measured using a cell counting kit-8 (Wako Pure Chemical Co.).

\section{Results}

\section{Collagens in liver under normal and pathologi- cal conditions}

\section{Quantitative analyses of collagens}

The formation of fibrous septa was observed in the livers which were injected with $\mathrm{CCl}_{4}$ for 7 weeks (Fig. 1A panel 2 ). From this histological diagnosis, we judged these to be fibrotic livers. After 10 weeks of $\mathrm{CCl}_{4}$ injection, thicker fibrous septa joining the adjacent central veins and portal veins were observed, as were regenerative nodules (Fig. 1A panel 3). These histological observations indicated that cirrhosis had been induced in this liver. In these experiments, the hydroxyproline contents per gram wet weight of liver in fibrotic liver and cirrhotic liver were 1.8-fold and 3.0-fold higher than that in normal liver that taken from the same age of rat, respectively. Type I, type III and type V collagen were detected from normal, fibrotic and cirrhotic livers by SDS-PAGE after pepsin digestion (Fig. 1B). The bands of $\alpha 1(\mathrm{~V})$ and $\alpha 2(\mathrm{~V})$ were identified in normal, fibrotic and cirrhotic livers by western blotting. The amounts of type I, type III and type V collagen which were extracted by pepsin treatment was estimated by densitometric analysis after SDS-PAGE (Fig. 1C). In normal livers, 12 $\mu \mathrm{g}$ of type $\mathrm{V}$ collagen was contained in $1 \mathrm{~g}$ wet weight of liver, and this concentration increased as fibrosis (2.7-fold) and cirrhosis (4.6-fold) developed (Fig. 1C). On the other hand, the increase in the extractable type I collagen in cirrhotic livers was rather lower (1.6-fold) than in fibrotic livers (1.8-fold, Fig. 1C). The increase in type III collagen in fibrosis was 14-fold and in cirrhotic was 12-fold (Fig. 1C). This indicates that the increase in extractable type $\mathrm{V}$ collagen was a better index of the development of cirrhosis than the increase in type I collagen. Increases of type I and type III collagen were regarded to be a better marker for the initial pathological change of the liver.

\section{Type specific localization of collagen in liver}

The localizations of type I, type IV and type V collagen in normal and cirrhotic livers were observed by comparing with stellate cells stained by anti desmin antibody. In normal liver, stellate cells were scattered in the sinusoidal walls (Fig. 2A). Type IV collagen was located along with the sinusoidal walls (Fig. 2C), while the discontinuous localization patterns of type I (Fig. 2B) and type V (Fig. 2H) collagen around the sinusoidal walls rather resembled that of stellate cells. In cirrhosis, stellate cells were found in the fibrous septa (Fig. 2E), and type IV (Fig. 2G) and type V (Fig. 2H) collagen were located at the margin of thick fibrous septa. Dense deposition of type I collagen was observed throughout the core region of the fibrous septa. (Fig. 2F). 
A

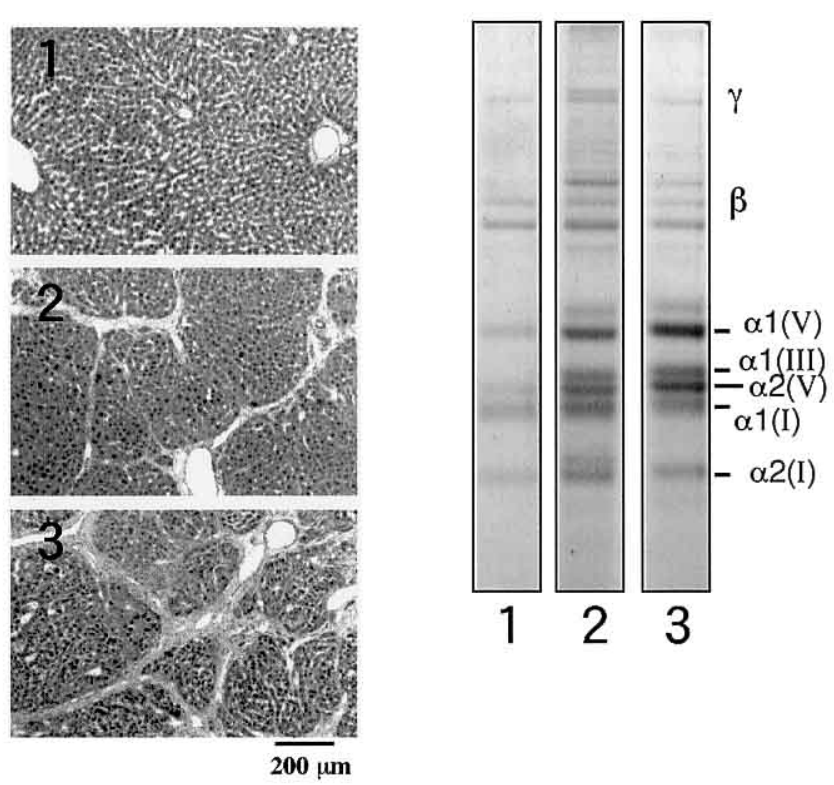

\section{C}
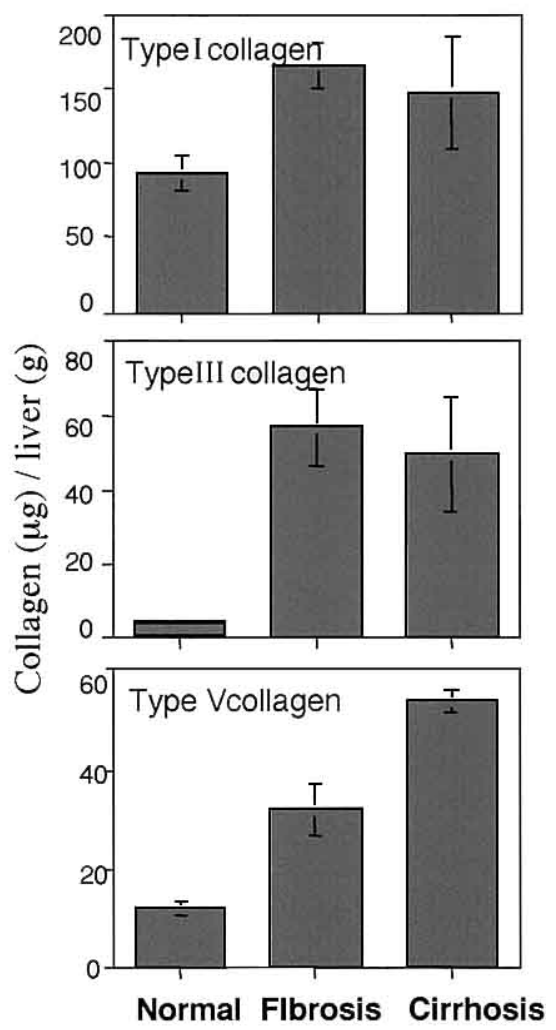

Bars indicate S.D

Fig. 1. Type specific collagen content in liver under normal, fibrosis and cirrhosis. In every panel, 1 indicates sample from normal liver, 2 from fibrotic liver and 3 from cirrhotic liver. A, The liver sections were stained with hematoxylin and eosin. B, The collagens extracted by pepsin treatment were analyzed by SDS-PAGE. C, Amounts of type I, type III and type V collagen were quantified from SDS-PAGE gel using the NIH image. Bars in C show s.d.

To examine the type specific distribution of collagen more clearly, double immunofluorescence microscopy under a confocal laser scanning microscope was done (Fig. 3 and 4). In normal liver, type I and type V collagen showed fibrous staining which corresponded to the reticular fibers. Type I and type $\mathrm{V}$ collagen were codistributed on the coarse fiber (Fig. 3F, large arrow). Type V collagen was also detected on the fine fiber on which type I collagen was absent (Fig. 3E and F, small arrow) as described elsewhere (Adachi et al. 1991). The localizations of type I and type IV collagen were different (Fig. 3A-C). The distributions of type IV and type $\mathrm{V}$ collagen partially overlapped the ends of fine fibers (Fig. $3 \mathrm{H}$ and I, arrowhead) under confocal-laser scanning microscope. In cirrhosis, the localization pattern of type $\mathrm{V}$ collagen was similar to that of type IV collagen which localized at the margin of thick fibrous septa (Fig. 4G and $\mathrm{H}$ ). However, when the localizations of type IV and type $\mathrm{V}$ collagen were compared in the superimposed image, type V collagen was localized just on the inner side of type IV deposition (Fig. 4I). The distribution of type V and type
IV collagen was different from that of type I collagen which was localized in the core region of the septa (Fig. 4A, C, D and F). Type $\mathrm{V}$ collagen seemed to be sandwiched between type I and type IV collagen depositions (Fig. 4F and I, arrowhead).

\section{Collagens in the culture system}

\section{Localization of type $V$ collagen in the culture of stellate cells and hepatocytes}

The interactions of liver-derived cells (stellate cells and hepatocytes) and type $\mathrm{V}$ collagen were examined in the culture system. The deposition patterns of collagens in the cultures were analyzed by immunofluorescence microscopy (Fig. 5). In the hepatocyte-culture, faint positive signals of type I collagen were observed in the cytosol, but type I collagen fibrils were not observed (Fig. 5A). The staining patterns of type III and type IV collagen were similar to that of type I collagen in the hepatocyte (data not shown). On the 

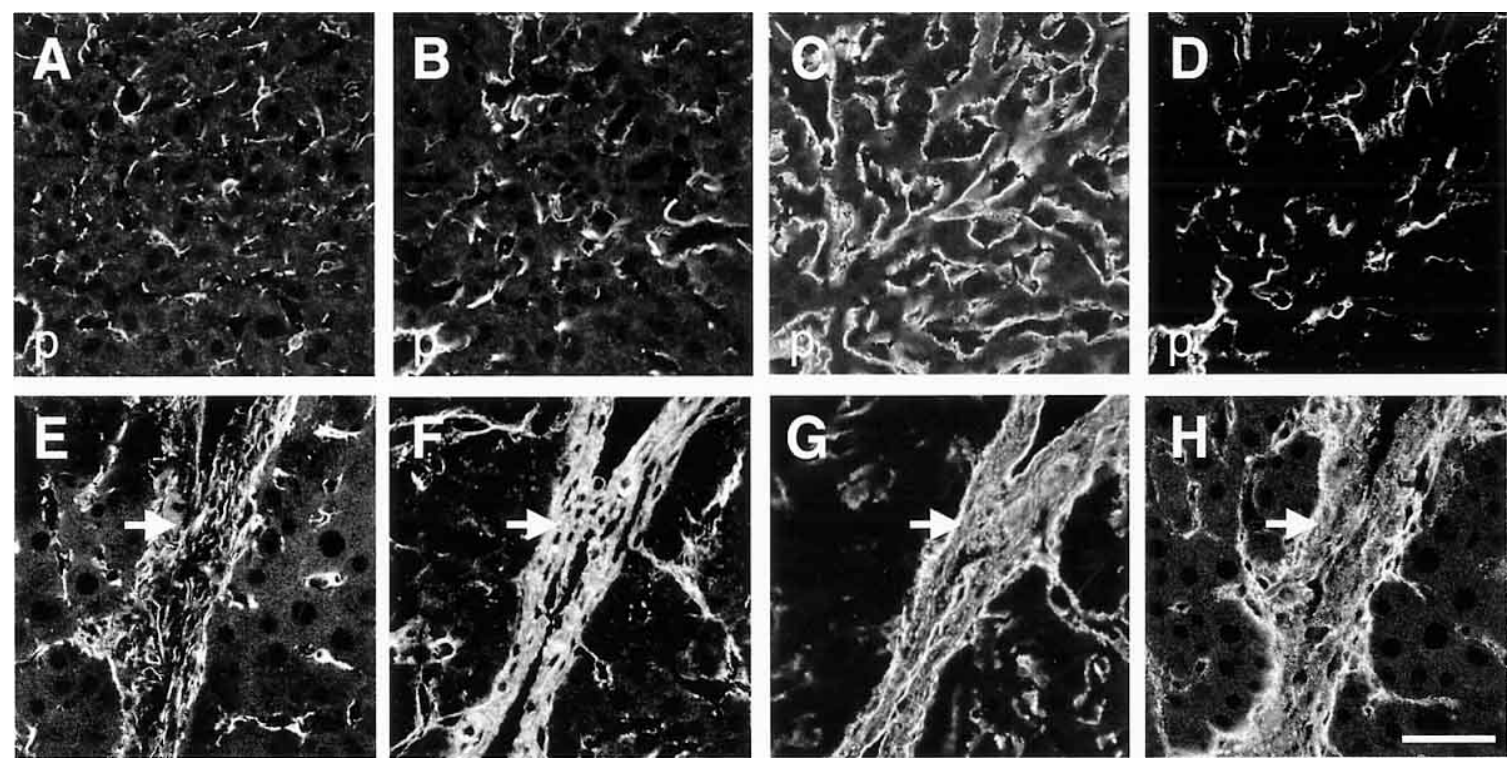

Fig. 2. Localizations of desmin, type I, type IV and type $\mathrm{V}$ collagen.Immunofluorescence microscopy of sequential sections of liver under normal and cirrhotic conditions. A-D: normal liver. E-H: cirrhosis. A and E: stained with anti desmin antibody. B and F: stained with anti type I collagen antibody. C and G: stained with anti type IV collagen antibody. D and H: stained with anti type V collagen antibody. In A to D, p indicates portal vein. In E to H, arrows indicate the thick fibrous septa. The bar indicates $50 \mu \mathrm{m}$.

other hand, type I collagen fibril was observed in stellate cell-culture (Fig. 5C). In the coculture, type I collagen fibers preferentially located on the stellate cells rather than on the hepatocyte colonies (Fig. 5B). In the hepatocytes-culture, the deposition of type $\mathrm{V}$ collagen was not observed (Fig. 5D). Several numbers of thin type $\mathrm{V}$ collagen fibrils were observed in the stellate cell-culture (Fig. 5F). In the coculture, type V collagen was prominently observed on the hepatocyte colonies that were surrounded by stellate cells, and was deposited in a granular form of aggregation (Fig. $5 \mathrm{E})$. The vertical distribution of type $\mathrm{V}$ collagen on hepatocytes in the coculture was examined using the $\mathrm{Z}$ sectioning mode with confocal laser scanning microscope. Figure 5G shows the sequential image taken from upper surface of cocultured cells at $1 \mu \mathrm{m}$ intervals (sequence numbers are indicated in Fig. 5G). Most of the type V collagen was located on the upper surface of hepatocyte colonies.

The spatial relations of type I, type IV and type V collagen in the coculture were further examined by double immunofluorescent staining (Fig. 6). Type I collagen fibers were observed on the stellate cells that were located around hepatocytes (Fig. 6A, in red), while the deposition of type $\mathrm{V}$ collagen was located on the hepatocyte colonies (Fig. 6A, in green). The distribution of type $\mathrm{V}$ collagen was segregated from that of type I collagen. Type IV collagen was also deposited on the hepatocyte colonies rather than on the stellate cells (Fig. 6B). However, the localizations of type $\mathrm{V}$ and type IV collagen were not exactly the same as those in the liver tissue as described in Figs. 3 and 4.

\section{Identification of collage- producing cells}

Prominent depositions of type I and type V collagen were observed in the stellate cell and coculture system (Fig. 5). This may indicate that type I and type V collagen were mainly produced by the stellate cells rather than by the hepatocytes. To investigate type V collagen-producing cells in the cultured system biochemically, we analyzed the expression of mRNA and the protein of type $\mathrm{V}$ collagen.

The expression of pro- $\alpha 1(\mathrm{~V})$ collagen and pro- $\alpha 2(\mathrm{~V})$ collagen mRNA was positively detected in the stellate cellculture and the coculture, but not in the hepatocytes (Fig. 7A). The expression of $\alpha$ SMA mRNA, which is a specific marker for activated stellate cells, was positive in the stellate cell-culture and in the coculture. This indicated that these stellate cells were in the activated phase.

Next, the translation level control of type $\mathrm{V}$ collagen was examined. $\alpha 1(\mathrm{~V})$ and $\alpha 2(\mathrm{~V})$ collagen chain were detected in the medium of both the coculture and stellate cell-culture, but type $\mathrm{V}$ collagen was not detected in the hepatocyteculture (Fig. 7B). We also analyzed type V collagen in the cell layer which was thought to have been deposited after secretion (Fig. 7C). Type I and type V collagen chains were detected in the fractions of both the coculture and the stellate cell-culture. However, neither type of collagen was detected in the hepatocyte-culture. 


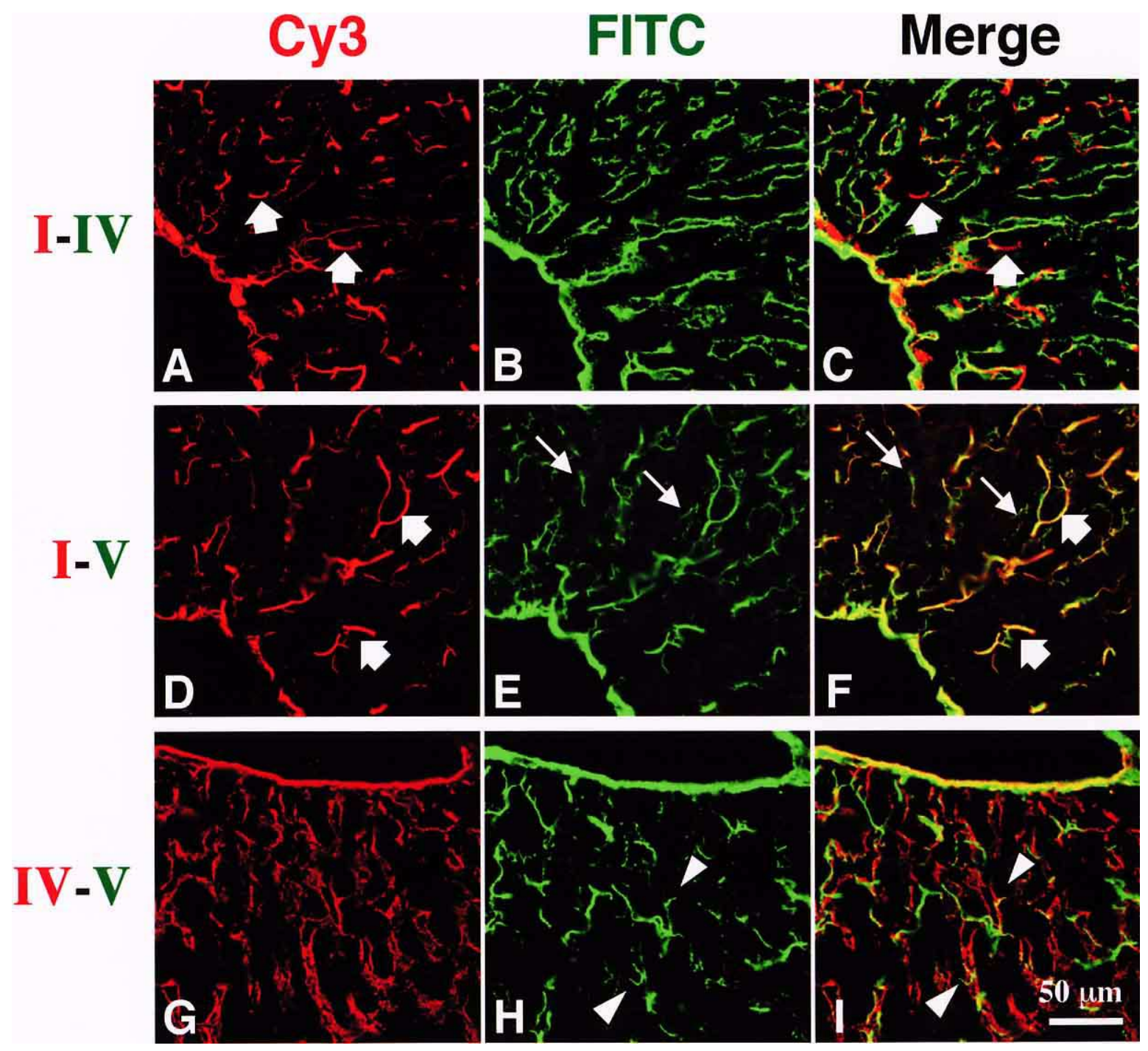

Fig. 3. Localizations of type I, type IV and type V collagen in normal liver.Double immunofluorescent staining was performed with collagen type-specific antibodies. A and D: type I collagen. B and G: type IV collagen. E and H: type V collagen. C, F and I are superimposed images constructed from the 2 images on the left side. We did not detect the fluorescent signal in control section (without primary antibodies) in this staining condition. In D and F, large arrows show the thick fibrils stained by anti type I collagen. In E and F, arrows show the thin fibrils stained by anti type V collagen. In H and I, arrowheads show overlapped stained positions by anti type V and type IV collagen antibodies.

\section{Type V collagen added exogenously was deposited pref- erentially on hepatocytes}

To investigate the deposition mechanism of type $\mathrm{V}$ collagen onto hepatocytes, type $\mathrm{V}$ collagen in a non-fibril form (collagen was dissolved in $5 \mathrm{mM}$ acetic acid) was added to the cultured cells exogenously. In the absence of the cells, type $\mathrm{V}$ collagen adhered diffusely to the dish surface (Fig. $8 \mathrm{C})$. When exogenous type $\mathrm{V}$ collagen was added to the hepatocyte-culture, type $\mathrm{V}$ collagen was deposited on and around the hepatocytes in granular form (Fig. 8B). When type $\mathrm{V}$ collagen was added to the coculture, concentrated depositions of type $\mathrm{V}$ collagen on hepatocytes were observed (Fig. 8E). Fig. 8D shows the cocultured stellate cell and hepatocytes without adding exogenous collagen. When we compared Fig. 8D and E, we assumed that the additive signal of type $\mathrm{V}$ collagen in Fig. 8E corresponded to the deposited exogenous type $\mathrm{V}$ collagen. In contrast, exogenously-added type I collagen was deposited on stellate cells in fibrous form, rather than on the hepatocytes (Fig. 8F). These results indicated that the depositions of exogenous collagen were regulated by the cells. Type V collagen located on hepatocyte colonies, while type I collagen was preferentially deposited on stellate cells. 


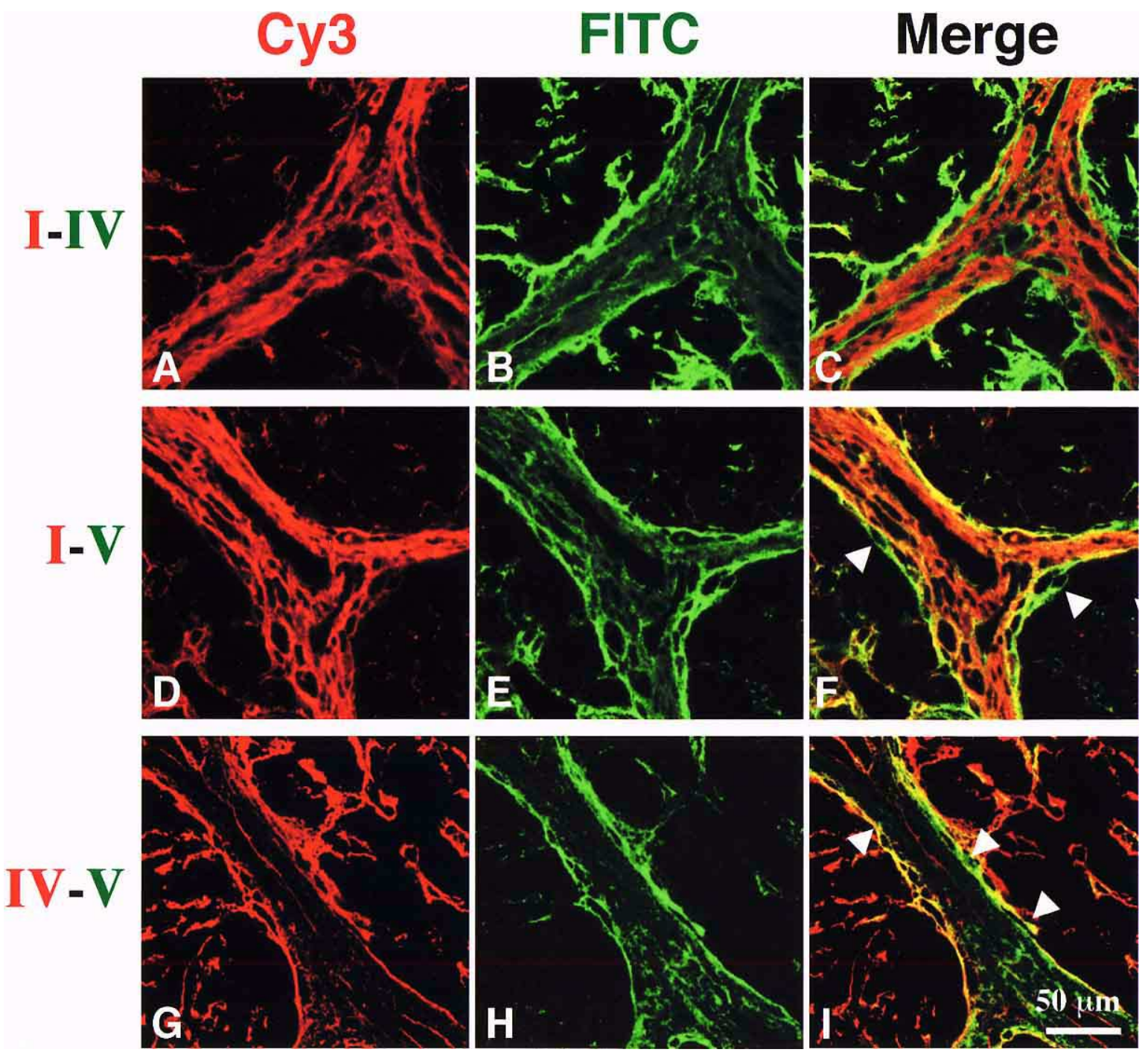

Fig. 4. Localizations of type I, type IV and type V collagen in cirrhotic liver. Double immunofluorescent staining was performed with collagen typespecific antibodies. A and D: type I collagen. B and G: type IV collagen. E and H: type V collagen. C, F and I are superimposed images constructed from the 2 images on the left side. We did not detect the fluorescent signal in control section (without primary antibodies) in this staining condition. In F and I, arrowheads show the type V collagen deposition sandwiched with type I and type IV collagen.

\section{Adhesion of stellate cells and hepatocytes to type I and type V collagen}

We examined the adhesion of stellate cells and hepatocytes to type I and type V collagen (Fig. 9). Stellate cells and hepatocytes attached to both type I and type $\mathrm{V}$ collagen within 30 minutes or 40 minutes, respectively. However, the adhesion-promoting activities of type $\mathrm{V}$ collagen to both stellate cells and hepatocytes cells were lower than those of type I collagen, with their respective values being $35 \%$ and $58 \%$ of those for type I collagen. After 1 day incubation, stellate cells formed aggregate and detached from the type $\mathrm{V}$ collagen surface, while hepatocytes remained attached and spread (data not shown). Both types of cells spread well on the type I collagen in longer incubation.

\section{Discussion}

As liver cirrhosis progresses, prominent fibrotic tissue is observed. It is well known that an increase in collagen deposition is the one of the main symptoms of this disease. In fact, the presence of collagen fragments in the serum has been used as a diagnostic marker for cirrhosis. For example, the presence of fragments of type IV and type III collagen (Misaki et al., 1990), fragment of type IV collagen (Obata et $a l ., 1989)$ and the fragments of type IV collagen and 7S do- 

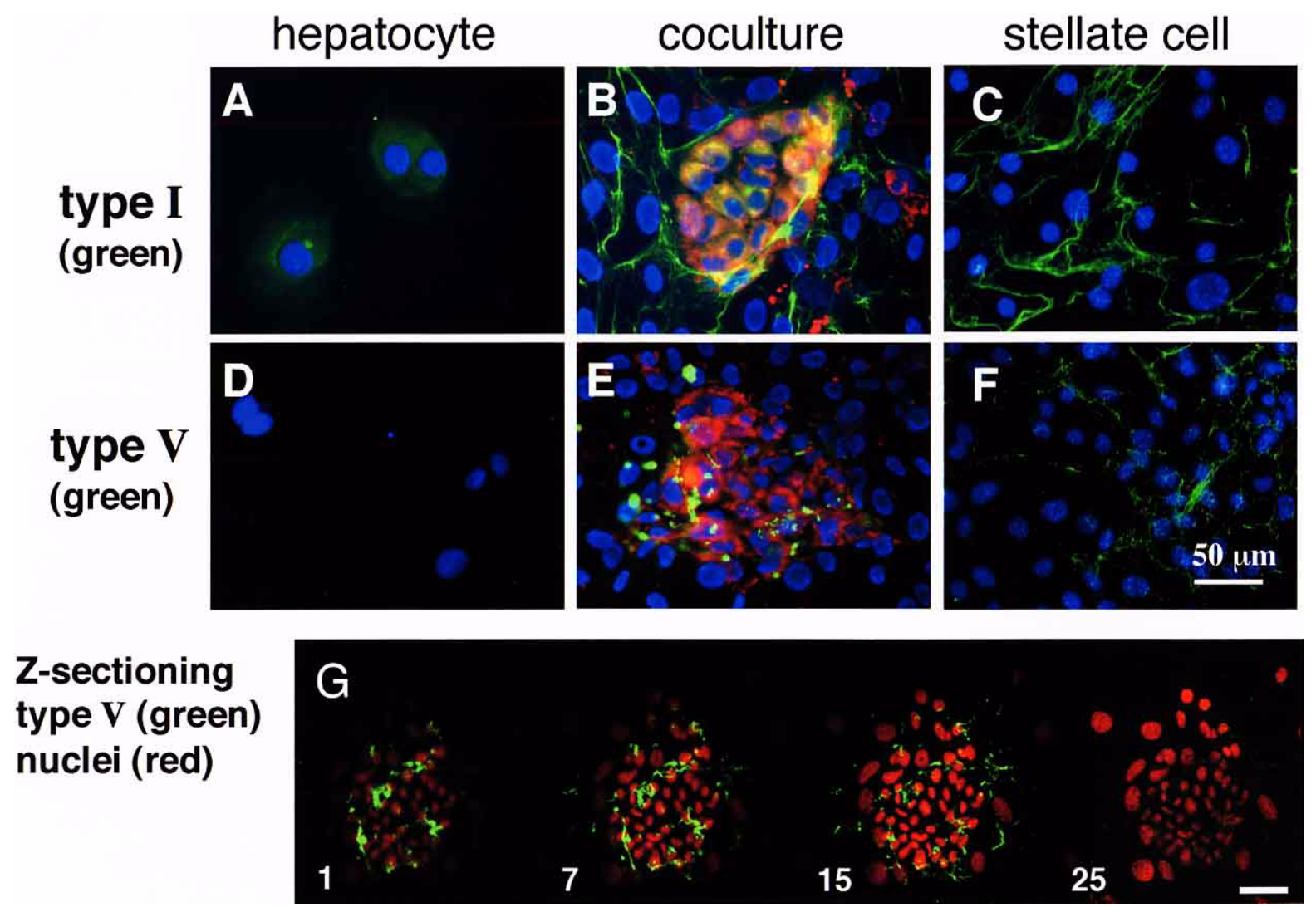

Fig. 5. Localizations of type I and type V collagens in the cultured cells. The depositions of collagens in the hepatocyte-culture (A and D), the coculture (B and $\mathrm{E})$ and the stellate cell-culture $(\mathrm{C}$ and $\mathrm{F})$ were observed by immunofluorescent staining with collagen type-specific antibodies. The top row shows type I collagen in green (A, B and C). The middle row shows type $\mathrm{V}$ collagen in green (D, E and F). Albumin producing hepatocytes in coculture were identified with Texas red conjugated rabbit anti-rat albumin in red (B and E). The nuclei were counter-stained with DAPI in blue. The vertical distribution of type $\mathrm{V}$ collagen was observed using the Z-sectioning mode of LSM410 (G). Scanning was performed at $1 \mu$ m intervals. The selected images are shown from upper side of cell to bottom. Numbers in figure indicate the distance from the surface of the cell ( $\mu \mathrm{m})$. Type V collagen is shown in green and the nuclei of the sellate cells and hepatocytes were stained with PI in red. The bar shows $50 \mu \mathrm{m}$.

main of type IV collagen (Murawaki et al., 1996) were used as markers. However, it was not known whether the increase in collagen is a pathogenic factor for cirrhosis or the result of an inflammatory process in the tissue. Here, we found that an increase in type $\mathrm{V}$ collagen was a more characteristic index of the progression of cirrhosis (Fig. 1). In the residual tissue of pepsin treatment, type $\mathrm{V}$ collagen was not detected but type I and type III collagen remained. From this result, we assumed that the increase of extractable type $\mathrm{V}$ in cirrhosis results in the increase of type $\mathrm{V}$ collagen production. On the other hand, the reason for the increase of pepsin extractable type I and type III collagen in pathogenic liver is not clear at present, that is whether it is due to the change of extractability or production or both.

Characteristic distributions of type $\mathrm{V}$ collagen were also observed in the liver. In normal liver, the patterns of type $\mathrm{V}$ collagen distribution resembled those of type I collagen (Fig. 2B and D). In cirrhosis, type V collagen deposition was observed at the margin of the fibrous septa along with type IV collagen (Fig. 2G and H). By double immunofluorescence microscopy, more detailed observation was achieved (Figs. 3 and 4). In normal liver, the signal of type $\mathrm{V}$ collagen was detected on the thinner fibril as previously reported (Adachi et al., 1991). On the thick fibril, type I and type $\mathrm{V}$ collagen were codistributed. On the ends of the fine type V collagen containing fibrils, type IV collagen overlapped with type V collagen (Fig. 3I). These results are not contradicted by a previous report that described type V collagen as a component of the lamina densa (Roll et al., 1980). Under electron microscope, Adachi and Hayashi found that thinner collagen fibrils, either type $\mathrm{V}$ collagen or hybrid fibril type $\mathrm{V}$ collagen, and other fibular collagens were frayed at the end which merged with the lamina densa in the pancreas, placenta and oral mucosa tissues (Adachi and Hayashi, 1994). These researchers proposed a model in which the epithelia, which grew on the basement membrane, were anchored to the underlying connective tissue via thin type $\mathrm{V}$ collagen fibrils. They also pointed out the 
A
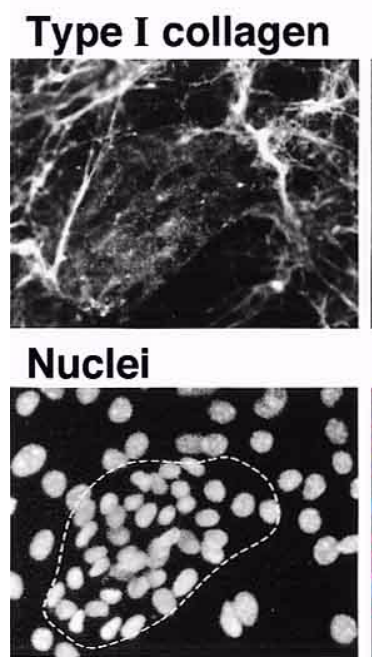

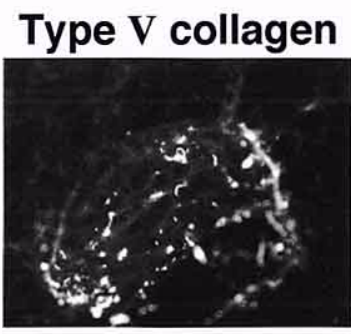

Merge

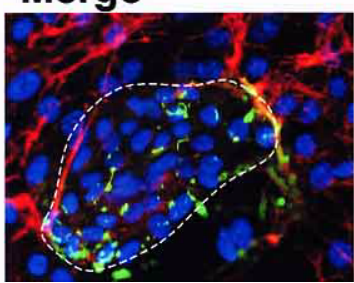

B
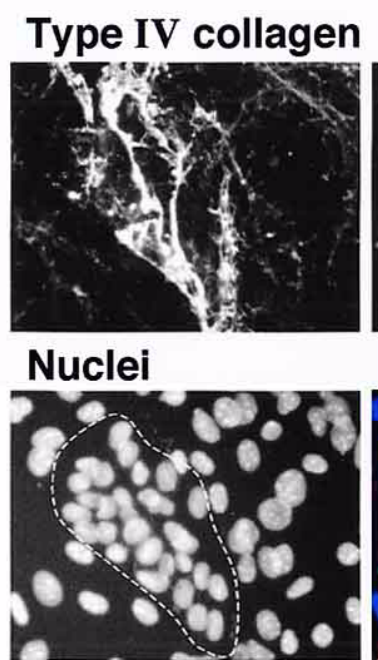

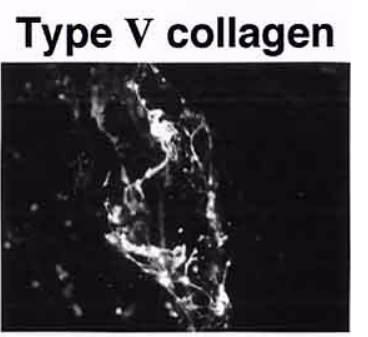

Merge

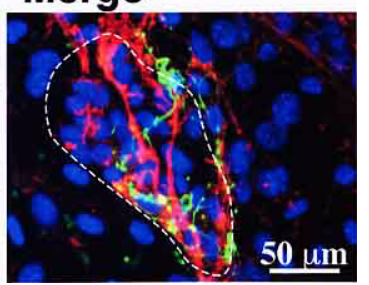

Fig. 6. Deposition patterns of types I, type IV and type V collagen in the coculture system.A. Double immunofluorescent staining with anti type I collagen antibody was followed by Cy3-conjugated second antibody (red), and anti-type V collagen antibody was followed by FITC-conjugated second antibody (green). B. Double immunofluorescent staining with anti-type IV collagen antibody was followed by Cy3-conjugated second antibody (red), and anti-type V collagen antibody was followed by FITC-conjugated second antibody (green). Nuclei were stained with DAPI (blue). The hepatocyte colonies are encircled with a broken line.

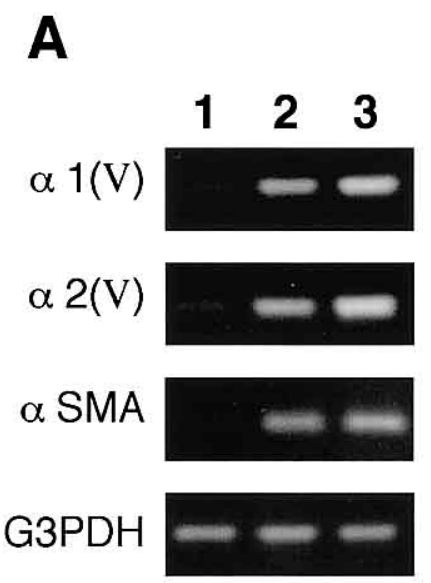

B

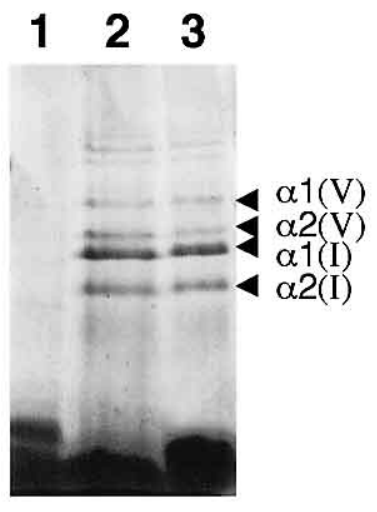

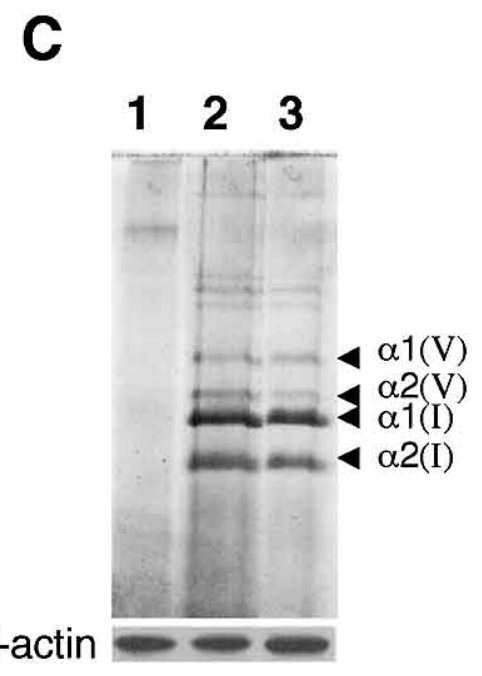

Fig. 7. Expression of mRNA, secretion, and translation level of type $V$ collagen in cultured cells. In every lane, 1 indicates the sample from hepatocyteculture, 2 from coculture hepatocyte and stellate cell and 3 from stellate cell-culture. A, The expressions of both $\alpha 1(\mathrm{~V})$ and $\alpha 2(\mathrm{~V})$ mRNA were measured by PCR. B, Collagen in same volume of conditioned media was analyzed by SDS-PAGE after pepsin digestion. C, Collagen from the cell layer (deposited collagen and collagen in the cell) was analyzed by SDS-PAGE after pepsin digestion. Cell number was adjusted by $\beta$ actin which was detected by western blotting using the sample before the pepsin digestion.

possibility that the association of type IV and type V collagen occurred in the cirrhotic liver (Adachi et al., 1997). In cirrhosis, the amount of collagen increased and the distributions of type I and type IV collagen were clearly separated (Fig. 4A, B and C). In cirrhosis, we postulated that the fibrous septa side, where the stellate cells were dominant region, corresponded to the underlying connective tissue, while the outside of the fibrous septa where was rich in hepatocytes, corresponded to the epithelia. The type $\mathrm{V}$ collagen deposition sandwiched between type I and type IV 
collagen (Fig. 4F and I) implies the anchoring function of type $\mathrm{V}$ collagen containing fibril in the tissue.

To investigate the mechanism of the deposition of type $\mathrm{V}$ collagen in liver, we developed a coculture system which used purified hepatocytes and activated stellate cells. In the coculture, type I collagen was mainly located on the stellate cells, and type IV collagen and type $\mathrm{V}$ collagen were located on the colony of hepatocytes. Type V collagen was especially prominent at the interface of the hepatocytes and stellate cells in the coculture (Figs. 5 and 6). In every culture condition we attempted, type $\mathrm{V}$ collagen was produced by stellate cells both in the mRNA and at the protein level (Figs. 5 and 7). Hata et al. reported that cloned rat hepatocytes and primarily cultured hepatocytes produced type IV and type V collagen in addition to type I and type III collagen (Hata et al., 1980 and 1985). Our results on type $\mathrm{V}$ collagen producing cells seem to contradict theirs. In immunofluorescence microscopy of hepatocyte culture, a positive signal for type I collagen was detected in the cytoplasm (Fig. 5A), but type V collagen was not observed. Although the difference cannot be easily explained, it is possible that it is due to differences in culture condition (in our culture, DMSO was added to hepatocyte-culture), or the inadequate amount of type $\mathrm{V}$ collagen produced in our detection system.

As the type-specific collagen depositions were seemed achieved by the cell, we tested the ability of the cell to regulate collagen deposition by adding monomeric collagen exogenously to the culture. Type I collagen formed fibrils on the stellate cell layer, and type V collagen was deposited on the hepatocyte colony (Fig. 8). The granular deposition of type $\mathrm{V}$ collagen was similar to that of endogenous collagen produced by the cell (Figs. 5 and 6). These results suggested that collagen which was produced mainly by stellate cells, was secreted into the medium and then deposited differentially according to the guidance of the underlying cells.

Once we had determined the specific localization of type $\mathrm{V}$ collagen in liver and in the coculture system, the question arose as to the mechanism governing the formation of these structures. We examined the adhesion of stellate cells and hepatocytes onto the collagens (Fig. 9). The adhesion of stellate cells to type $\mathrm{V}$ collagen was relatively poorer than the adhesion of hepatocytes to type $\mathrm{V}$ collagen. In a longer incubation period, stellate cells formed an aggregate and stopped proliferation (paper in preparation). The adhesion of both stellate cells and hepatocytes to type I collagen was thought to be mediated by $\beta 1$ subunit containing integrins. It has been reported that $\alpha 1 \beta 1$ integrin may be involved in the adhesion of hepatocytes (Gullberg et al., 1992), and that $\alpha 1 \beta 1$ and $\alpha 2 \beta 1$ integrin are responsible for the adhesion of activated stellate cells (Racine-Samson et al., 1997). It has been reported that type $\mathrm{V}$ collagen induces the migration of epidermal cells (Stenn et al., 1979), smooth muscle cells (Grotendorst et al., 1981) and endothelial cells (Yamamoto et al., 1992). Another report described that type V collagen inhibited the cell adhesion and proliferation of lung epithelial cells (Parekh et al., 1998). Ruggiero et al. reported that
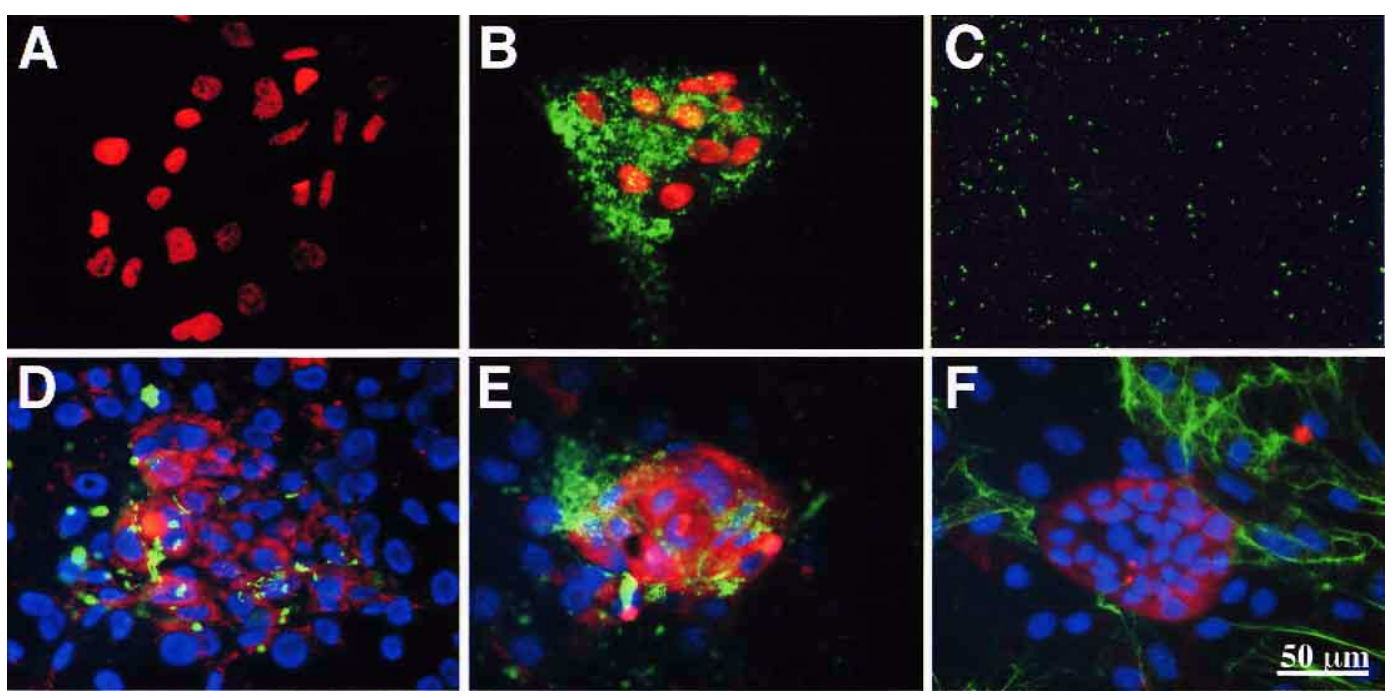

Fig. 8. Addition of exogenous type V collagen into cultured cells. The type V or FITC labeled type I collagen was added to the cultured cells exogenously. Twenty-four hours after adding collagens, type V collagen was immunofluorescent stained with anti-type V collagen antibody and FITC labeled type I collagen was observed under the fluorescent microscope. A, hepatocyte-culture without exogenous collagen. B, type V collagen added on hepatocytes. C, type V collagen added on glass surface without cells. D, coculture without exogenous collagen. E, type V collagen added on coculture. F, FITC-type I collagen added on coculture. In B to E, type V collagen is shown in green. In F, type I collagen is shown in green. The nuclei were stained with PI in red (A and $\mathrm{B}$ ) or DAPI in blue (D, E and F). Hepatocyte colonies were stained with anti rat albumin in red (D, E and F). 


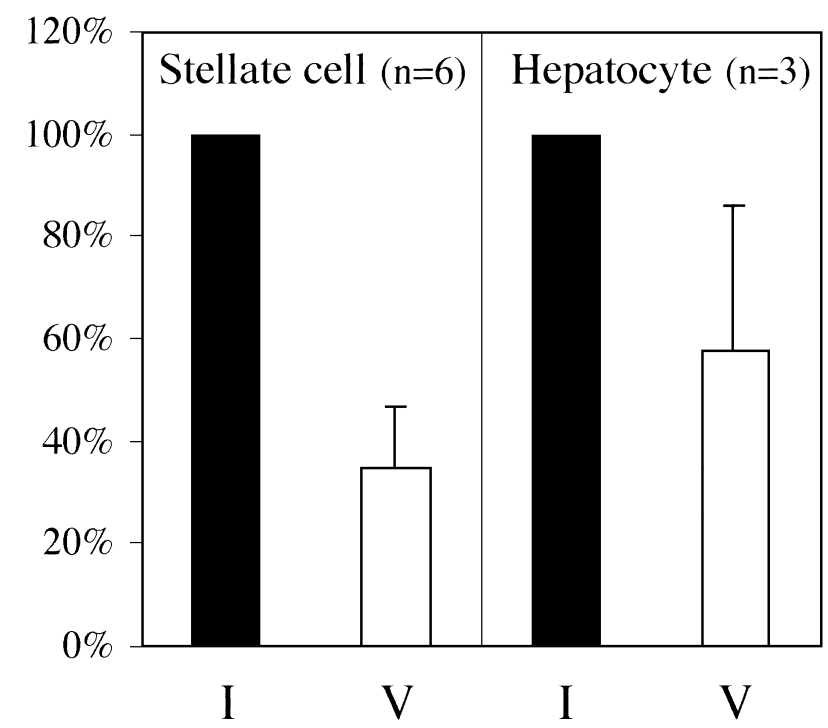

Fig. 9. Adhesion of stellate cells and hepatocytes onto type I and type V collagen. Cells were plated on type I and type V collagen. After 30 minutes (stellate cell) or 40 minutes (hepatocyte), the adhered cells were measured using a cell counting kit- 8 . Here, the relative percentage of adhesion is shown, when the adhesion of cells on type I collagen was expressed as $100 \%$. Here the average of 6 or 3 independent experiments is shown. $\alpha 1 \beta 1$ and $\alpha 2 \beta 1$ integrins mediated cell adhesion of HT1080 (a human fibrosarcoma cell) and HBL100 (a human mammary epithelial cell) to native type $\mathrm{V}$ collagen (Ruggiero et al., 1996), but recently Knight et al. found that the Adomain of $\alpha 1 \beta 1$ and $\alpha 2 \beta 1$ integrins recognized the GFOGER ( $\mathrm{O}$ indicates hydroxyproline) sequence in the triple helical collagen which is not present in bovine and human type V collagen (Knight et al., 2000). Although the cell receptor for type $\mathrm{V}$ collagen has not been determined, the difference affinity of cells for type $\mathrm{V}$ collagen may create a specific arrangement for collagen deposition in cultured system and in tissue liver. The mechanism for forming a specific distribution of type $\mathrm{V}$ collagen can be explained as follows. In a cirrhotic liver or in culture, stellate cells actively produce collagen. Type I collagen may be deposited on the producing cell, which has a high affinity for type I collagen. On the other hand, type V collagen, which has a low affinity for stellate cells, is pushed away from the cells and deposited on the interface region between the stellate cells and hepatocytes. The same mechanism may be at work in normal liver, but the distribution of type $\mathrm{V}$ collagen is emphasized in a system in which collagens are actively produced.

Finally we discussed the possible biological function of
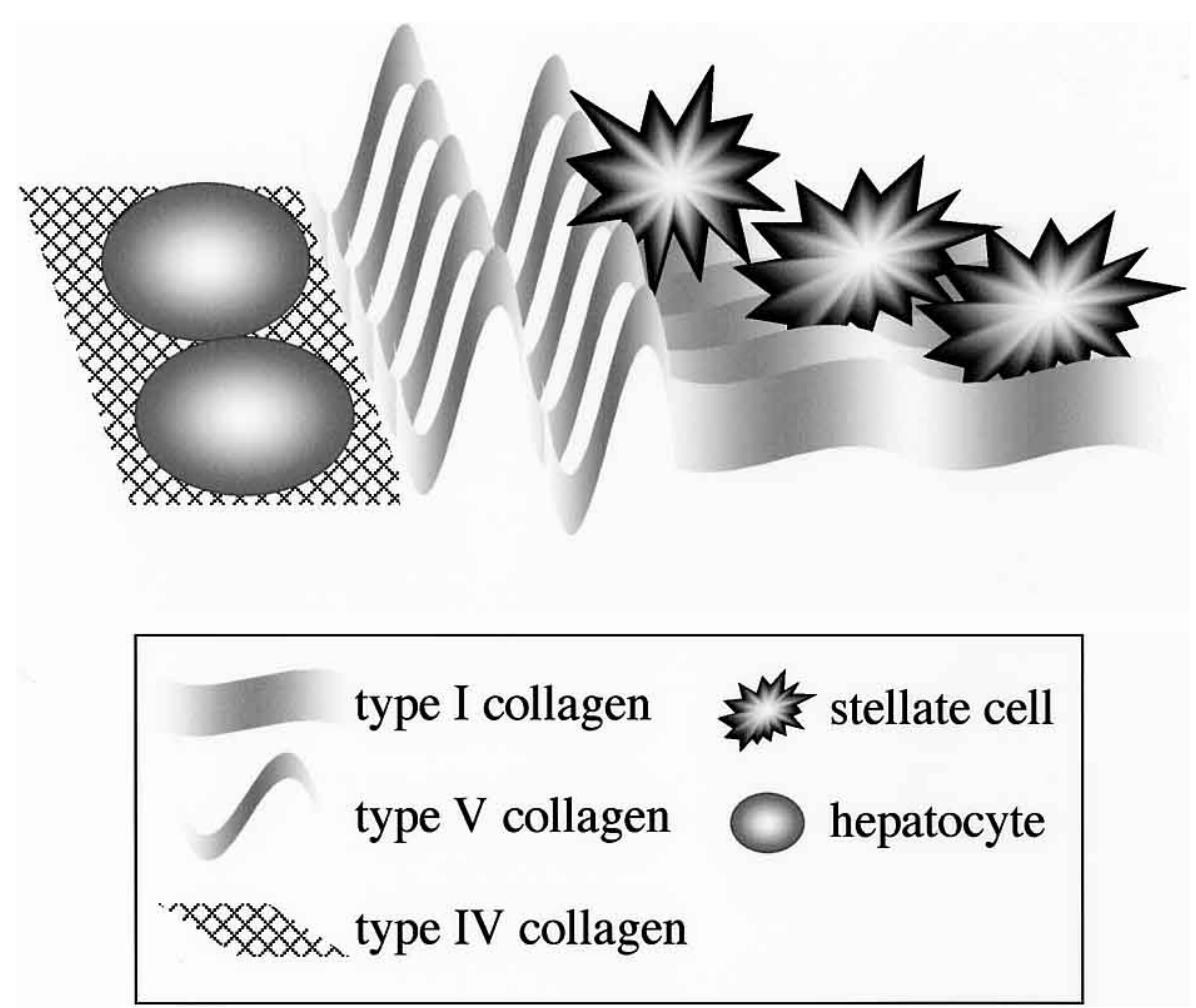

Fig. 10. Hypothetical model for the role of type V collagen in the liver. It is suggested that type V collagen has an anchoring role between the collagen fibril in the connective tissue and the lamina densa. In addition to the anchoring role, our results suggest that type $\mathrm{V}$ collagen works as an embankment between parenchyma and fibrous septa in cirrhosis. 
type $\mathrm{V}$ collagen in this structure. The following two roles for the minor fibrillar collagens (type V and XI) were proposed (Adachi et al., 1997). One is regulation of fibrillogenesis by limiting the diameter of fibrils made from major collagens (type I, II and III) and the other is the anchoring role between the collagen fibril in the connective tissue and the lamina densa through interactions with type $\mathrm{V}$ and type IV collagen. In addition to this, our cell adhesion experiment indicated that type $\mathrm{V}$ collagen aids the segregation of the stellate cells and hepatocytes. Our results agree with the anchoring role of type $\mathrm{V}$ collagen and this structure was reconstructed in culture. In addition to this, our cell adhesion experiment indicated that type $\mathrm{V}$ collagen segregates the stellate cells from the hepatocyte colony. We supposed that type $\mathrm{V}$ collagen work as an embankment in cirrhosis, and that this type $\mathrm{V}$ collagen containing fibril prevents excess fibrosis of the liver parenchyma by regulating the activity of the surrounding stellate cells (Fig. 10).

Acknowledgments. We thank Dr. E. Adachi and Dr. Y. Koyama for their advice and helpful discussions, Dr. N. Obara, Dr. H. Sato and Dr. K. Asahina for kindly providing the PCR probes, and Mr. T. Ebihara and Mr. K. Iijima for their support of the experiments.

\section{References}

Adachi, E. and Hayashi, T. 1986. In vitro formation of hybrid fibrils of type V collagen and type I collagen. Limited growth of type I collagen into thick fibrils by type V collagen. Connect. Tissue Res., 14: 257-266.

Adachi, E., Hayashi, T., and Hashimoto, P.H. 1991. A comparison of the immunofluorescent localization of collagen types I, III, and V with the distribution of reticular fibers on the same liver sections of the snow monkey (Macaca fuscata) Cell Tissue Res., 264: 1-8.

Adachi, E. and Hayashi, T. 1994. Anchoring of epithelia to underlying connective tissue: evidence of frayed ends of collagen fibrils directly merging with meshwork of lamina densa. J. Electron Microsc., (Tokyo). 43: 264-271.

Adachi, E., Hopkinson, I., and Hayashi, T. 1997. Basement-membrane stromal relationships: interactions between collagen fibrils and the lamina densa. Int. Rev. Cytol., 173: 73-156.

Bader, A., Knop, E., Kern, A., Boker, K., Fruhauf, N., Crome, O., Esselmann, H., Pape, C., Kempka, G., and Sewing, K.F. 1996. 3-D coculture of hepatic sinusoidal cells with primary hepatocytes - design of an organotypical model. Exp. Cell Res., 226: 223-233.

Birk, D.E., Fitch, J.M., Babiarz, J.P., Doane, K.J., and Linsenmayer, T.F. 1990. Collagen fibrillogenesis in vitro: interaction of types I and V collagen regulates fibril diameter. J. Cell Sci., 95: 649-657.

Caron, J.M. 1990. Induction of albumin gene transcription in hepatocytes by extracellular matrix proteins. Mol. Cell Biol., 10: 1239-1243.

Friedman, S.L. 1993. Seminars in medicine of the Beth Israel Hospital, Boston. The cellular basis of hepatic fibrosis. Mechanisms and treatment strategies. N. Engl. J. Med., 328: 1828-1835.

Geerts, A., Lazou, J.M., De Bleser, P., and Wisse, E. 1991. Tissue distribution, quantitation and proliferation kinetics of fat-storing cells in carbon tetrachloride-injured rat liver. Hepatology, 13: 1193-1202.

Gressner, A.M. 1996. Mediators of hepatic fibrogenesis. Hepatogastroenterology, 43: 92-103.

Grotendorst, G.R., Seppa, H.E., Kleinman, H.K., and Martin, G.R. 1981. Attachment of smooth muscle cells to collagen and their migration toward platelet-derived growth factor. Proc. Natl. Acad. Sci. USA, 78:
3669-3672.

Gullberg, D., Gehlsen, K.R., Turner, D.C., Ahlen, K., Zijenah, L.S., Barnes, M.J., and Rubin, K. 1992. Analysis of $\alpha 1 \beta 1, \alpha 2 \beta 1$ and $\alpha 3 \beta 1$ integrins in cell-collagen interactions: identification of conformation dependent $\alpha 1 \beta 1$ binding sites in collagen type I. Embo. J., 11: 38653873.

Hata, R., Ninomiya, Y., Nagai., Y., and Tsukada, Y. 1980. Biosynthesis of interstitial type of collagen by albumin-producing rat liver parenchymal cell (hepatocyte) clones in culture. Biochemistry, 19: 169-176.

Hata, R., Ninomiya, Y., Sano, J., Konomi, H., Hori, H., Sunada, H., Tanaka, S., Kabuki, K., Nagai, Y., and Tsukada, Y. 1985. Activation of collagen synthesis in primary culture of rat liver parenchymal cells (hepatocytes). J. Cellular Physiol., 122: 333-342.

Hattori, S., Shirai, T., Suzuki, K., Irie, S., Hori, H., and Nagai, Y., 1996. Assay of collagenase activity using FITC-labeled type II collagen as a substrate (in Japanese). Connective Tissue, 28: 27-33.

Hayashi, T., and Nagai, Y. 1980. The anomalous behavior of collagen peptides on sodium dodecyl sulfate-polyacrylamide gel electrophoresis is due to the low content of hydrophobic amino acid residues. $J$. Biochem., 87: 803-808.

Hynes, R.O. 1992. Integrins: versatility, modulation, and signaling in cell adhesion. Cell, 69: 11-25.

Knight, C.G., Morton, L.F., Peachey, A.R., Tuckwell, D.S., Farndale, R. W., and Barnes, M.J. 2000. The collagen-binding A-domains of integrins $\alpha 1 \beta 1$ and $\alpha 2 \beta 1$ recognize the same specific amino acid sequence, GFOGER, in native (triple-helical) collagens. J. Biol. Chem., 275: 3540.

Knittel, T., Aurisch, S., Neubauer, K., Eichhorst, S., and Ramadori, G. 1996. Cell-type-specific expression of neural cell adhesion molecule (N-CAM) in Ito cells of rat liver. Up-regulation during in vitro activation and in hepatic tissue repair. Am. J. Pathol., 149: 449-462.

Marchant, J.K., Hahn, R.A., Linsenmayer, T.F., and Birk, D.E. 1996. Reduction of type V collagen using a dominant-negative strategy alters the regulation of fibrillogenesis and results in the loss of corneal-specific fibril morphology. J. Cell Biol., 135: 1415-1426.

Mendler, M., Eich-Bender, S.G., Vaughan, L., Winterhalter, K.H., and Bruckner, P. 1989. Cartilage contains mixed fibrils of collagen types II, IX, and XI. J. Cell Biol., 108: 191-197.

Misaki, M., Shima, T., Yano, Y., Sumita, Y., Kano, U., Murata, T., Watanabe, S., and Suzuki, S. 1990. Basement membrane-related and type III procollagen-related antigens in serum of patients with chronic viral liver disease. Clin. Chem., 36: 522-524.

Mooney, D., Hansen, L., Vacanti, J., Langer, R., Farmer, S., and Ingber, D. 1992. Switching from differentiation to growth in hepatocytes: control by extracellular matrix. J. Cell Physiol., 151: 497-505.

Murata, K., Kudo, M., Onuma, F., and Motoyama, T. 1984. Changes of collagen types at various stages of human liver cirrhosis. Hepatogastroenterology, 31: 158-161.

Murawaki, Y., Ikuta, Y., Koda, M., Yamada, S., and Kawasaki, H. 1996. Comparison of serum 7S fragment of type IV collagen and serum central triple-helix of type IV collagen for assessment of liver fibrosis in patients with chronic viral liver disease. J. Hepatol., 24: 148-154.

Obata, K., Iwata, K., Ichida, T., Inoue, K., Matsumoto, E., Muragaki, Y., and Ooshima, A. 1989. One step sandwich enzyme immunoassay for human type IV collagen using monoclonal antibodies. Clin. Chim. Acta., 181: 293-303.

Ogawa, K., Suzuki, J., Mukai, H., and Mori, M. 1986. Sequential changes of extracellular matrix and proliferation of Ito cells with enhanced expression of desmin and actin in focal hepatic injury. Am. J. Pathol., 125: 611-619.

Parekh, T.V., Wang, X.W., Makri-Werzen, D.M., Greenspan, D.S., and Newman, M.J. 1998. Type V collagen is an epithelial cell cycle inhibitor that is induced by and mimics the effects of transforming 
growth factor $\beta 1$. Cell Growth Differ., 9: 423-433.

Racine-Samson, L., Rockey, D.C., and Bissell, D.M. 1997. The role of $\alpha 1 \beta 1$ integrin in wound contraction. A quantitative analysis of liver myofibroblasts in vivo and in primary culture. J. Biol. Chem., 272: 30911-30917.

Rojkind, M. and Ponce-Noyola, P. 1982. The extracellular matrix of the liver. Coll. Relat. Res., 2: 151-175.

Rojkind, M., Novikoff, P.M., Greenwel, P., Rubin, J., Rojas-Valencia, L., de Carvalho, A.C., Stockert, R., Spray, D., Hertzberg, E.L., and Wolkoff, A.W. 1995. Characterization and functional studies on rat liver fat-storing cell line and freshly isolated hepatocyte coculture system. Am. J. Pathol., 146: 1508-1520.

Roll, F.J., Madri, J.A., Albert, J., and Furthmayr, H. 1980. Codistribution of collagen types IV and AB2 in basement membranes and mesangium of the kidney. An immunoferritin study of ultrathin frozen sections. $J$. Cell Biol., 85: 597-616.

Ruggiero, F., Comte, J., Cabanas, C., and Garrone, R. 1996. Structural requirements for $\alpha 1 \beta 1$ and $\alpha 2 \beta 1$ integrin mediated cell adhesion to collagen V. J. Cell Sci., 109: 1865-1874.

Scott, J.E., Bosworth, T.R., Cribb, A.M., and Gressner, A.M. 1994. The chemical morphology of extracellular matrix in experimental rat liver fibrosis resembles that of normal developing connective tissue. Virchows Arch., 424: 89-98.

Seglen, P.O. 1976. Preparation of isolated rat liver cells. Methods Cell Biol., 13: 29-83.

Senoo, H. and Hata, R, 1993. Isolation of perisinusoidal stellate cells (vitamin A-storing cells, fat-storing cells) of the rat liver (in Japanese). Connective Tissue, 25: 129-137.

Stenn, K.S., Madri, J.A., and Roll, F.J. 1979. Migrating epidermis produces $\mathrm{AB} 2$ collagen and requires continual collagen synthesis for movement. Nature, 277: 229-232.

Tanikawa, K. 1994. Serum marker for hepatic fibrosis and related liver pathology. Pathol. Res. Pract., 190: 960-968.

Tateno, C. and Yoshizato, K. 1996. Long-term cultivation of adult rat hepatocytes that undergo multiple cell divisions and express normal parenchymal phenotypes. Am. J. Pathol., 148: 383-392.

Tateno, C., Takai-Kajihara, K., Yamasaki, C., Sato, H., and Yoshizato, K. 2000. Heterogeneity of growth potential of adult rat hepatocytes in vitro. Hepatology, 31: 65-74.

Tsutsumi, M., Takase, S., Urashima, S., Ueshima, Y., Kawahara, H., and Takada, A. 1996. Serum markers for hepatic fibrosis in alcoholic liver disease: which is the best marker, type III procollagen, type IV collagen, laminin, tissue inhibitor of metalloproteinase, or prolyl hydroxylase? [see comments]. Alcohol Clin. Exp. Res., 20: 1512-1517.

Unakar, N.J. 1966. p-Hydroxypropiophenone vs CCL $_{4}$-induced injury. Arch. Pathol., 82: 170-177.

Wu, J. and Norton, P.A. 1996. Animal models of liver fibrosis. Scand J. Gastroenterol., 31: 1137-1143.

Yamada, K.M. 1997. Integrin signaling. Matrix Biol., 16: 137-141.

Yamagata, S., Miwa, M., Tanaka, K., and Yamagata, T. 1982. FBJ virusinduced osteosarcoma has type $\mathrm{V}$ collagen consisting of A, B and C-like chains in addition to type I collagen. Biochem. Biophys. Res. Commun., 105: 1208-1214.

Yamamoto, K., Yamamoto, M., and Noumura, T. 1992. Disassembly of Factin filaments in human endothelial cells cultured on type V collagen. Exp. Cell Res., 201: 55-63.

(Received for publication, June 1, 2001

and in revised form, September 14, 2001) 